\title{
Progression of Hip Joint Deformity during the Management of Pelvic Insufficiency Fracture in a Patient with Rheumatoid Arthritis: A Case Report
}

Kenji Ikuta ${ }^{1}$, Yuko Waguri-Nagaya ${ }^{2}$, Masahiro Nozaki ${ }^{1}$, Jun Mizutani ${ }^{1}$, Hideyuki Goto ${ }^{1}$, Masaaki Kobayashi ${ }^{1}$ and Takanobu Otsuka

${ }^{1}$ Department of Orthopaedic Surgery, Nagoya City University Graduate School of Medical Sciences, Mizuho-Ku, Nagoya 467-8601, Japan

${ }^{2}$ Department of Joint Surgery for Rheumatic Diseases, Nagoya City University Graduate School of Medical Sciences, Mizuho-Ku, Nagoya 467-8601, Japan

*Corresponding author: Yuko Waguri-Nagaya, Department of Joint Surgery for Rheumatic Diseases, Nagoya City University Graduate School of Medical Sciences, Mizuho-Ku, Nagoya 467-8601, Japan, Tel: 0528538200; E-mail: waguri@med.nagoya-cu.ac.jp

Rec date: Oct 27, 2014, Acc date: Oct 29, 2014, Pub date: Oct 31, 2014

Copyright: ( 2014 Ikuta K et al. This is an open-access article distributed under the terms of the Creative Commons Attribution License, which permits unrestricted use, distribution, and reproduction in any medium, provided the original author and source are credited.

\section{Abstract}

Introduction: An insufficiency fracture is a type of non-traumatic fracture caused by bone fragility that most commonly occurs in the pelvis and lower extremities. Although sacral insufficiency fracture is not uncommon, its diagnosis is often delayed or missed. We here report the case of SIF with rheumatoid arthritis that occurred during the pre-operative waiting time for total hip arthroplasty.

Case presentation: A 57-year-old woman with rheumatoid arthritis presented with sacral insufficiency fracture that occurred during the pre-operative waiting time for total hip arthroplasty. During the four months after the onset of the sacral insufficiency fracture, her pubis, ischium and acetabulum fractured and deformity of her left hip joint gradually progressed. Total hip arthroplasty was performed using bone grafting onto the acetabulum from the autogenous femoral head. The findings upon clinical examination and the patient's assessment of function were excellent at the time of the most recent follow-up.

Conclusion: When total hip arthoplasty is performed in patients with severe osteoporosis or insufficiency fracture of the acetabulum, it is essential to avoid additional pelvic factures at the time of setting the acetabular cup component. Moreover, as a total hip arthoplasty might itself be a predisposing causative factor of pelvic insufficiency fracture, recurrence of insufficiency fractures should be monitored in those patients with the history. Aggressive intervention for osteoporosis might be necessary to prevent insufficiency fracture development.

Keywords: Rheumatoid arthritis; Insufficiency fracture; Total hip arthroplasty

\section{Introduction}

An Insufficiency Fracture (IF) is a type of non-traumatic fracture caused by bone fragility [1] that most commonly occurs in the pelvis and lower extremities [2]. Although Sacral Insufficiency Fracture (SIF) is not uncommon, its diagnosis is often delayed or missed [3]. Moreover, SIF patients can suffer complications involving IF of the pubis, ischium [4-6].

We recently encountered a case of SIF with Rheumatoid Arthritis (RA) that occurred during the pre-operative waiting time for Total Hip Arthroplasty (THA). Hip joint deformity of the affected side had acutely worsened and we recognized that it was necessary to pay attention to its progression as well as protrusio acetabuli after the SIF onset. The patient gave informed consent for data concerning her case to be submitted for publication.

\section{Case Report}

The patient was a 57-year-old woman who developed RA at the age of 27. She underwent a left elbow synovectomy at 49 years of age, a right Total Knee Arthroplasty (TKA) at 52, a left TKA at 53, and a right Total Hip Arthroplasty (THA) at 54. She was receiving medication of $7.5 \mathrm{mg}$ prednisolone daily, $4 \mathrm{mg}$ methotrexate weekly and $35 \mathrm{mg}$ alendronate weekly.

At the age of 55, she complained of left hip joint pain. Radiographs of the left hip joint were classified as grade III according to the Larsen classification system of RA [7] (Figure 1A).

A left THA was subsequently scheduled but, during the preoperative waiting time, severe lumbosacral pain and subcutaneous fluctuation of the sacral region (approximately $6 \mathrm{~cm}$ in diameter) occurred without trauma. There were no neurological insufficiencies. Radiographs showed no evident fracture line on the pelvis (Figure 1A) or lumbar spine (Figure 2).

Computed tomography (CT) and 3D-CT scanning disclosed longitudinal fracture lines in the bilateral sacral alae, but there were no signs of osteolysis or space-occupying lesions (Figure 3).

Magnetic resonance imaging (MRI) revealed a low intensity area on T1-weighted images and a mixture of high intensity and low intensity areas on T2-weighted images consistent with fractures. Bone Mineral Density (BMD) and the T-score using dual-energy X-ray absorptiometry (DEXA) in the lumbar spines were $0.627 \mathrm{~g} / \mathrm{cm} 2$ and -3.8 , respectively. Serum laboratory findings are shown in Table 1.

The severe lumbosacral pain greatly improved with conservative treatment using analgesics and subcutaneous fluctuation of the sacral region disappeared two months later. Radiographs revealed progression of the left femoral head deformity, and fracture of the 
Citation: Ikuta K, Waguri-Nagaya Y, Nozaki M, Mizutani J, Goto H, Kobayashi M, et al. (2014) Progression of Hip Joint Deformity during the Management of Pelvic Insufficiency Fracture in a Patient with Rheumatoid Arthritis: A Case Report. J Spine 3: 188. doi: $10.4172 / 2165-7939.1000188$

Page 2 of 4

bilateral pubic and ischial rami and the medial wall of the left acetabulum (Figure 1B and C). CT scans at four months after the onset of SIF showed no displacement of SIF but the formation of a callus was apparent (Figure 4).

Seven months after the onset of SIF, a left THA was performed by grafting an autogeneous femoral head onto the acetabulum. Postoperatively, a fracture of the left greater femoral trochanter occurred with no other symptoms. One year post-surgery, the allografts appeared to have united radiographically with no radiolucent lines visible between the graft and the acetabular cup (Figure 2D). The patient experienced complete relief of lumbosacral and hip pain and can walk with a T-cane. She now receives a recombinant human form of parathyroid hormone (teriparatide, $600 \mu \mathrm{g}$ per day) to medicate against osteoporosis. BMD in the lumbar spines improved from 0.627 $\mathrm{g} / \mathrm{cm}^{2}$ to $0.704 \mathrm{~g} / \mathrm{cm}^{2}$ within a year of using teriparatide.

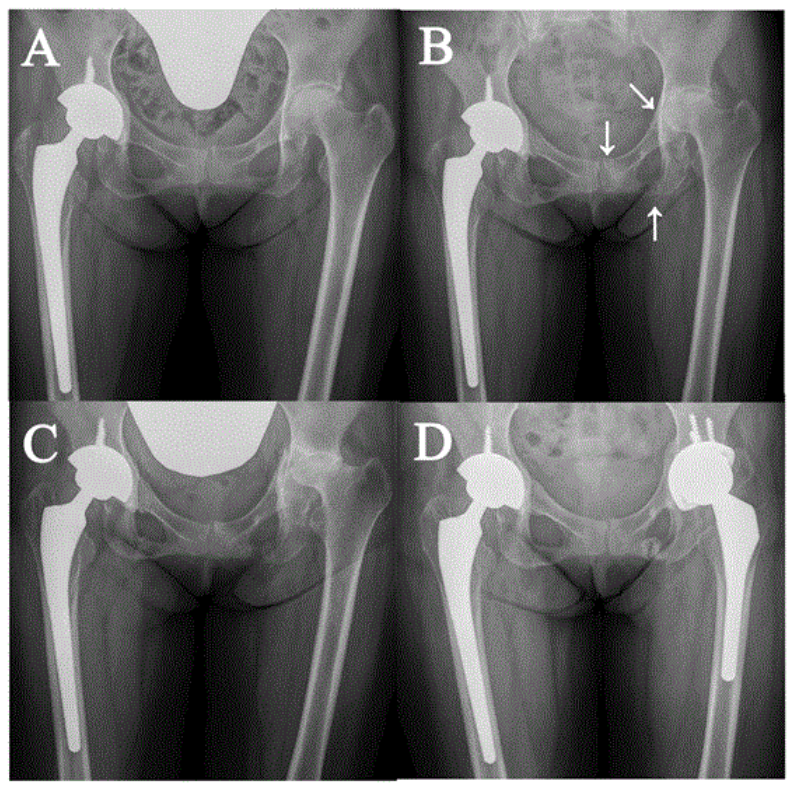

Figure 1: Radiographs of the hip joint at the time of SIF onset (A), after four months (B), and after seven months (C). IFs of bilateral pubis, ischium and left acetabulum were observed (arrow heads) and the left femoral head deformity had worsened. One year after left total hip arthroplasty, autogenous bone from the resected femoral head was successfully grafted to the acetabular floor (D).

\section{Discussion}

A characteristic of SIF lies in its difficulty to be diagnosed upon first examination [8], which is attributable to its nonspecific symptoms, unclear fracture lines, overlap with signs of intestinal gas pooling on radiographs $[9,10]$, and a tendency to focus on hip joint or lumbar spine diseases [1]. It is also difficult to distinguish SIF from inflammatory diseases and primary/metastatic bone tumors $[11,12]$. However, it is important to keep the possibility of SIF in mind in a patient with lumbosacral pain. In the present case, subcutaneous fluctuation of the sacral region caused by hematoma after sacral fracture was helpful in the correct diagnosis of SIF.

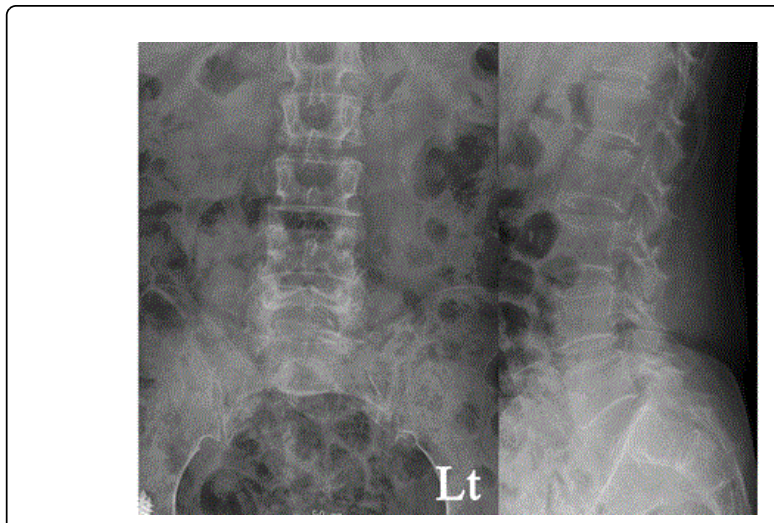

Figure 2: Radiographs of the lumbar spine taken at the first complaint of lumbosacral pain. No fracture line was evident.
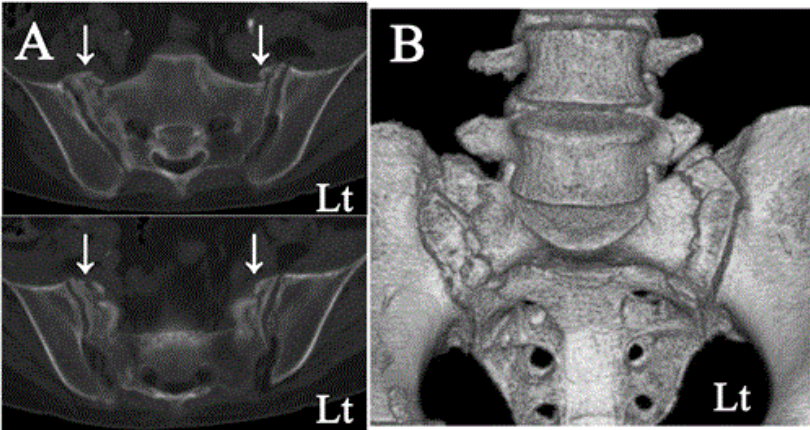

Figure 3: $\mathrm{CT}$ (A) and 3D-CT scans (B) disclosed longitudinal fracture lines (arrow heads) in the bilateral sacral alae. CT scans showed no signs of osteolysis or space-occupying lesions.

\begin{tabular}{|l|l|l|}
\hline Parameter & Measurement & Standard range \\
\hline White blood cells & $9800 / \mu \mathrm{l}$ & $3000-8500 / \mu \mathrm{l}$ \\
\hline Red blood cells & $458 \times 10^{4} / \mathrm{\mu l}$ & $378-499 \times 10^{4} / \mathrm{\mu l}$ \\
\hline Hemoglobin & $13.7 \mathrm{~g} / \mathrm{dl}$ & $10.8-14.9 \mathrm{~g} / \mathrm{dl}$ \\
\hline Platelets & $27.4 \times 10^{4} / \mu \mathrm{l}$ & $15.0-36.1 \times 10^{4} / \mu \mathrm{l}$ \\
\hline C-reactive protein & $1.66 \mathrm{mg} / \mathrm{dl}$ & $\sim 0.30 \mathrm{mg} / \mathrm{dl}$ \\
\hline $\begin{array}{l}\text { Erythrocyte sedimentation } \\
\text { rate }\end{array}$ & $7 \mathrm{~mm} / \mathrm{h}$ & $\sim 16 \mathrm{~mm} / \mathrm{h}$ \\
\hline Rheumatoid factor & $368 \mathrm{U} / \mathrm{ml}$ & $\sim 10 \mathrm{U} / \mathrm{ml}$ \\
\hline Matrix metalloproteinase-3 & $117.1 \mathrm{ng} / \mathrm{ml}$ & $17.3-59.7 \mathrm{ng} / \mathrm{ml}$ \\
\hline Alkaline phosphatase & $1036 \mathrm{U} / \mathrm{l}$ & $115-359 \mathrm{U} / \mathrm{l}$ \\
\hline Calcium & $9.5 \mathrm{mg} / \mathrm{dl}$ & $8.7-10.3 \mathrm{mg} / \mathrm{dl}$ \\
\hline
\end{tabular}

Table 1: Serum laboratory findings at the onset of sacral insufficiency fracture 
Citation: Ikuta K, Waguri-Nagaya Y, Nozaki M, Mizutani J, Goto H, Kobayashi M, et al. (2014) Progression of Hip Joint Deformity during the Management of Pelvic Insufficiency Fracture in a Patient with Rheumatoid Arthritis: A Case Report. J Spine 3: 188. doi: $10.4172 / 2165-7939.1000188$

Page 3 of 4

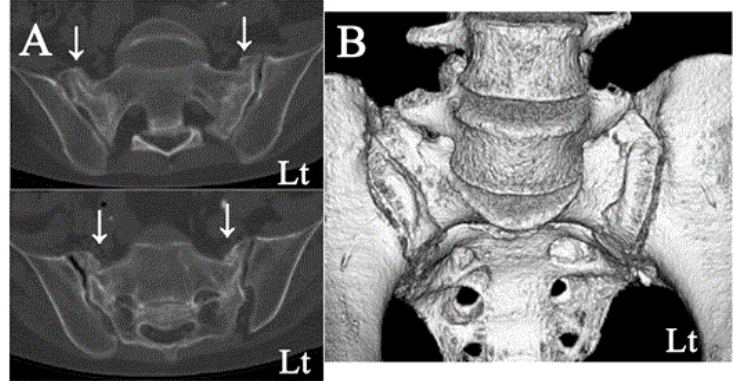

Figure 4: CT (A) and 3D-CT scans (B) four months after the onset of SIF revealed no displacement of SIF but showed the formation of a callus.

Routine radiography of the spine and pelvis is usually inconclusive and offers limited diagnostic sensitivity. Although CT is considered the gold standard modality for diagnosing occult SIF as it can delineate bony details [13], it can also be useful to conduct screening using MRI and bone scintigraphy. Indeed, a previous study reported that bone scintigraphy revealed the 'Honda sign' in $43 \%$ of all cases with SIF [14].

Treatment of SIF is usually conservative, for example, percutaneous sacroplasty was previously used as an effective strategy to treat persistent lumbosacral pain $[15,16]$. In the present case, BMD did not increase sufficiently following alendronate treatment, so teriparatide, a recombinant form of parathyroid hormone, was considered instead as it has been shown to reduce severe back pain after a vertebral fracture [17]. Within a year of teriparatide treatment, the BMD of the current patient increased from $0.627 \mathrm{~g} / \mathrm{cm}^{2}$ to $0.704 \mathrm{~g} / \mathrm{cm}^{2}$. Such adequate management of osteoporosis can help prevent subsequent occurrences of IF.

In RA patients, the sacrum and the metatarsal bones are common sites of IF [18]. Therefore the possibility of SIF must be considered in all patients with long-standing RA, especially in women with poorly controlled disease and those undergoing oral glucocorticoid therapy $[19,20]$. In the present case, IFs of the pubic body, ischium and acetabulum developed after the onset of SIF. It has previously been shown that the likelihood of developing pubic IF increases if stress accumulates near the pubic symphysis from anterior dislocation of the load caused by SIF-associated pelvic ring instability $[9,21,22]$.

Progression of the hip joint deformity was observed in the current patient after the onset of pelvic IFs. We carried out a literature search of this topic and found very few reports of SIF as a complication of progressive RA hip joint deformity [19]. This progression could be attributable to unbalanced stress concentrations on the hip joint from changes in pelvic inclination and lumbar spine curving, as well as RAinduced joint destruction. When THA is performed in patients with severe osteoporosis or IF of the acetabulum, it is essential to avoid additional pelvic factures at the time of setting the acetabular cup component. Moreover, as THA might itself be a predisposing causative factor of SIF [23], recurrence of pelvic IF should be monitored in those patients with a history of pelvic IF.

In conclusion, aggressive intervention for osteoporosis might be necessary to prevent IF development and it is particularly important to monitor the progression of hip joint deformity after SIF onset in patients with RA. Successful post-operative results, as in the present study, can be achieved by cautious maneuvers and acetabular bone grafting during THA.

\section{Consent}

Written informed consent was obtained from the patient for publication of this case report and accompanying images. A copy of the written consent is available for review by the Editor-in-Chief of this journal.

\section{Competing Interests}

The authors declare that they have no competing interests.

\section{Author Contributions}

KI, YWN, MN, JM, HG and MK were involved in the conception, design and interpretation. KI and YWN wrote the manuscript. KI, JM and TO collected data, reviewed relevant published reports and provided the images. All authors read and approved the final manuscript.

\section{References}

1. Tsiridis E, Upadhyay N, Giannoudis PV (2006) Sacral insufficiency fractures: current concepts of management. Osteoporos Int 17: 1716-1725.

2. Ozaki D, Shirai Y, Nakayama Y, Uesaka S (2000) A case report of insufficiency fracture of the Fossa acetabuli in a patient with rheumatoid arthritis. J Nippon Med Sch 67: 267-270.

3. Blake SP, Connors AM (2004) Sacral insufficiency fracture. Br J Radiol 77: 891-896.

4. Peh WC (2000) Intrafracture fluid: a new diagnostic sign of insufficiency fractures of the sacrum and ilium. Br J Radiol 73: 895-898.

5. De Smet AA, Neff JR (1985) Pubic and sacral insufficiency fractures: clinical course and radiologic findings. AJR Am J Roentgenol 145: 601-606.

6. Davies AM, Evans NS, Struthers GR (1988) Parasymphyseal and associated insufficiency fractures of the pelvis and sacrum. Br J Radiol 61: 103-108.

7. Larsen A, Dale K, Eek M (1977) Radiographic evaluation of rheumatoid arthritis and related conditions by standard reference films. Acta Radiol Diagn (Stockh) 18: 481-491.

8. Schindler OS, Watura R, Cobby M (2007) Sacral insufficiency fractures. J Orthop Surg (Hong Kong) 15: 339-346.

9. White JH, Hague C, Nicolaou S, Gee R, Marchinkow LO, et al. (2003) Imaging of sacral fractures. Clin Radiol 58: 914-921.

10. KarataÅŸ M, BaÅŸaran C, Ozg Ã¹/4l E, Tarhan C, AÄŸildere AM (2008) Postpartum sacral stress fracture: an unusual case of low-back and buttock pain. Am J Phys Med Rehabil 87: 418-422.

11. Cooper KL, Beabout JW, Swee RG (1985) Insufficiency fractures of the sacrum. Radiology 156: 15-20.

12. Peh WC, Khong PL, Yin Y, Ho WY, Evans NS, et al. (1996) Imaging of pelvic insufficiency fractures. Radiographics 16: 335-348.

13. Gotis-Graham I, McGuigan L, Diamond T, Portek I, Quinn R, et al. (1994) Sacral insufficiency fractures in the elderly. J Bone Joint Surg Br 76: $882-886$

14. Finiels H, Finiels PJ, Jacquot JM, Strubel D (1997) [Fractures of the sacrum caused by bone insufficiency. Meta-analysis of 508 cases]. Presse Med 26: 1568-1573.

15. Butler CL, Given CA 2nd, Michel SJ, Tibbs PA (2005) Percutaneous sacroplasty for the treatment of sacral insufficiency fractures. AJR Am J Roentgenol 184: 1956-1959. 
Citation: Ikuta K, Waguri-Nagaya Y, Nozaki M, Mizutani J, Goto H, Kobayashi M, et al. (2014) Progression of Hip Joint Deformity during the Management of Pelvic Insufficiency Fracture in a Patient with Rheumatoid Arthritis: A Case Report. J Spine 3: 188. doi: $10.4172 / 2165-7939.1000188$

Page 4 of 4

16. Frey ME, DePalma MJ, Cifu DX, Bhagia SM, Daitch JS (2007) Efficacy and safety of percutaneous sacroplasty for painful osteoporotic sacra insufficiency fractures: a prospective, multicenter trial. Spine (Phila Pa 1976) 32: 1635-1640.

17. Nevitt MC, Chen P, Dore RK. Reduced risk of back pain following teriparatide treatment: a meta-analysis. Osteoporos Int. 2006;17:273-80.

18. Peris P (2002) Stress fractures in rheumatological practice: clinical significance and localizations. Rheumatol Int 22: 77-79.

19. Fukunishi S, Fukui T, Nishio S, Imamura F, Yoshiya S (2009) Multiple pelvic insufficiency fractures in rheumatoid patients with mutilating changes. Orthop Rev (Pavia) 1: e23.
20. West SG, Troutner JL, Baker MR, Place HM (1994) Sacral insufficiency fractures in rheumatoid arthritis. Spine (Phila Pa 1976) 19: 2117-2121.

21. Leroux JL, Denat B, Thomas E, Blotman F, Bonnel F (1993) Sacral insufficiency fractures presenting as acute low-back pain. Biomechanical aspects. Spine (Phila Pa 1976) 18: 2502-2506.

22. Linstrom NJ, Heiserman JE, Kortman KE, Crawford NR, Baek S, et al. Anatomical and biomechanical analyses of the unique and consistent locations of sacral insufficiency fractures. Spine (Phila $\mathrm{Pa}$ 1976). 2009;34:309-15.

23. Pelvic insufficiency fracture imaging. http://emedicine.medscape.com/ article/394406-overview\#a01 